\title{
Massive gastrointestinal haemorrhage associated with ileal lymphoid hyperplasia in Gaucher's disease
}

\author{
D.R. Jones, J. Hoffman, R. Downie and M. Haqqani
}

Walton Hospital, Liverpool, Merseyside, UK

\begin{abstract}
Summary: A case report of adult type I Gaucher's disease is described, with profound terminal ileal haemorrhage in association with ileal lymphoid hyperplasia. Peroperative ileal endoscopy localized the segment involved allowing an appropriate resection and successful outcome for the patient.
\end{abstract}

\section{Introduction}

Adult or type I Gaucher's ${ }^{1}$ disease is characterized by hepatic and splenic accumulation of glucocerebroside, an intermediate product of membrane lipid metabolism. Bone involvement is frequent but only rarely are other organs affected; cerebral involvement is not a major feature and life expectancy is usually normal unlike the neuronopathic varieties, types II and III.

The pattern of disease is heterogeneous, probably due to variation of mutation in the gene for the affected enzyme: lysosomal glucosylceramide-betaglucosidase. $^{2}$

Bleeding complications arise as a result of thrombocytopaenia associated with hypersplenism; the usual manifestations are petechial skin haemorrhage, bruising and epistaxis. Gastrointestinal haemorrhage is uncommon, haemopericardium has been reported ${ }^{3}$ as have oesophageal varices. ${ }^{4} \mathrm{We}$ describe a case of massive gastrointestinal haemorrhage in association with ileal lymphoid hyperplasia in a patient with adult Gaucher's disease.

\section{Case report}

A 47 year old male patient with adult, type I Gaucher's disease was admitted following a profound rectal loss of blood whilst driving. He had had no previous significant rectal bleeding but was due to be admitted electively for excision of haemorrhoids. There had been no warning other than a sudden urge to defaecate.

Correspondence: D.R. Jones, M.Ch., F.R.C.S., 556 Pensby Road, Thingwall, Wirral L61 7UE, UK.

Present address: Vascular Studies Unit, Bristol Royal Infirmary, Bristol, UK.

Accepted: 19 November 1990
At the age of 4 he had undergone splenectomy for splenomegaly and had been treated conservatively for bone deformity of the knees in childhood. A Billroth I gastrectomy was undertaken at the age of 22 and a Meckel's diverticulum with an adhesive band had been excised some 17 years later. In the previous 9 years to his present admission he had a further 3 admissions for small bowel obstruction presumed to be adhesive in origin.

On admission he was pale, hypotensive, with a blood pressure of $80 / 40 \mathrm{mmHg}$ and a tachycardia of 100 /minute. Full blood count showed a haemoglobin of $9.3 \mathrm{~g} / \mathrm{dl}$ and a normal platelet count of $234 \times 10^{9} /$ litre. Examination of the blood film showed the changes of hyposplenism with nucleated red cells. Prothrombin time and kaolin-cephalin clotting time were not elevated. Serum alkaline phosphatase and transaminase enzymes were normal as were plasma electrolytes and urea.

Following resuscitation and cessation of bleeding, arrangements were made for an elective colonoscopy. On the day of the examination he had a further massive rectal loss of dark blood and underwent urgent sigmoidoscopy and colonoscopy. Other than haemorrhoids no identifiable mucosal lesion was visualized up to the level of the hepatic flexure at which blood was seen to be oozing from a more proximal site.

Immediate laparotomy revealed gross hepatomegaly but no other abdominal mass. There was blood within the lumen of the whole of the colon and $10 \mathrm{~cm}$ of the terminal ileum although the bowel was palpably normal. Peroperative flexible endoscopy with a gastroscope inserted through a small enterotomy in the ileum localized the site of bleeding to the terminal $20 \mathrm{~cm}$ of ileum up to the ileocaecal valve. The right colon and affected terminal ileum was resected to include any possible right colonic angiodysplasia. Postoperative recovery was uneventful and the patient was free of symptoms at review some 6 weeks later. 
Examination of the opened specimen showed the mucosal surface to be covered in a carpet of pale nodules approximately $1 \mathrm{~mm}$ diameter but more confluent nearer the ileocaecal valve. An area of telangiectasia near the ileocaecal valve marked the site of origin of haemorrhage. No mucosal abnormality was identified within the colon.

Histology of the ileal mucosa showed widespread reactive benign lymphoid hyperplasia with submucosal oedema and haemorrhage. Gaucher cells were not seen within the specimen. No vascular abnormality was apparent within the bowel wall (Figure 1).

Microscopy of a needle core liver biopsy showed no evidence of cirrhosis but engorgement of the parenchyma with typical Gaucher cells and distortion of the normal liver architecture.

\section{Discussion}

Haemorrhagic complications of Gauchers' disease are more usually associated with thrombocytopaenia due to splenomegaly ${ }^{5}$ and bone marrow infiltration with glucocerebroside. Immune thrombocytopaenia sufficient to cause retroperitoneal haematoma has been reported in one patient with Gaucher's disease ${ }^{6}$ and was suspected as the cause of thrombocytopaenia in another. ${ }^{7}$ Gastrointestinal bleeding secondary to thrombocytopaenia is uncommon although buccal mucosal petechiae have been noted. ${ }^{8}$ Patients may have low platelet counts for many years before bleeding diatheses develop. Moderate hepatic dysfunction secondary to accumulation of glycolipid causes elevation of blood liver enzymes and abnormal radioisotope uptake scans. The partial thromboplastin time may be prolonged due to an apparent deficiency of several clotting factors, particularly factor IX, in vitro. ${ }^{9}$ Hypofibrinogenaemia has not been reported. The case described above had a life-threatening haemorrhage some 40 years following splenectomy in the presence of a normal platelet count and normal clotting studies.

The liver is invariably involved in type I Gaucher's disease although development of cirrhosis is infrequent.$^{10}$ Frank portal hypertension has been reported but is uncommon although oesophageal varices leading to gastrointestinal haemorrhage can occur ${ }^{11-13}$ and rarely may be massive and fatal. ${ }^{4}$

Lymphoid hyperplasia of Peyer's patches does not feature in reports of Gaucher's disease although Gaucher cells are frequently found in Peyer's patches. ${ }^{1}$ Peyer's patch lymphoid hyperplasia is an uncommon finding but is associated with acute and chronic inflammatory conditions. It may give rise to ulceration and bleeding most notably in untreated typhoid infection. ${ }^{14}$

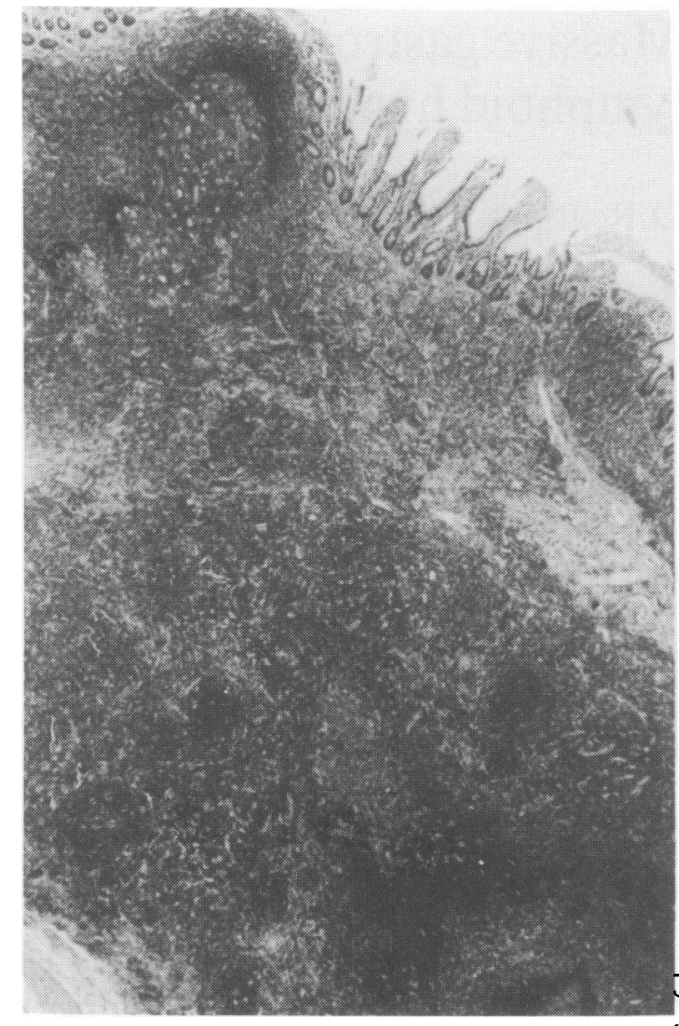

Figure 1 Marked lymphoid hyperplasia of the ileum with a few remaining villi. H\&E stain $\times 100$.

The diagnosis and management of caecal or ileal haemorrhage presents problems, particularly when the bleeding is massive and life-threatening. Colonoscopy is most useful for chronic bleeding or in stable patients when bleeding has ceased. The presence of active bleeding requires several hours of preparation and an experienced colonoscopist. Accuracy of diagnosis is variable ${ }^{15-17}$ but this approach allows the possibility of endoscopic therapy with laser, ${ }^{18,19}$ bipolar electrocoagulation or heater probe. ${ }^{19}$

Abdominal scintigraphy using technetium-99m sulphur colloid or technetium-99m labelled red cells may be helpful to determine fresh bleeding ${ }^{20}$ but accurate localization of bleeding is not possible.

Selective mesenteric angiography is the investigation of choice for localization of active bleeding unless the urgency of the situation precludes any further delay. Small intestinal localization of angiodysplasia in the elderly has been useful using this method. ${ }^{21}$

Barium studies can usefully identify small bowel tumours but may delay diagnosis and treatment in the presence of massive bleeding. 
Brearley et al. $^{22}$ have shown that laparotomy is an important diagnostic tool in the management of intestinal bleeding of obscure origin particularly when bleeding is rapid and urgent intervention is indicated. Interoperative endoscopy has been employed to locate small bowel lesions which are impalpable, particularly angiodysplasias. The colonoscope may be passed orally ${ }^{23}$ or rectally, ${ }^{24}$ manipulating the endoscope into the small bowel. Smaller diameter endoscopes can be introduced via an enterotomy, as in the case described above, for more rapid intraluminal bowel inspection or transillumination of the bowel wall to identify vascular

\section{References}

1. Brady, R.O. \& Barranger, J.A. Glucosylceramide lipidoses: Gaucher's disease. In: Stanbury, J.L. \& Brown, M.S. (eds). The Metabolic Basis of Inherited Disease, 5th edition. McGraw-Hill, New York, 1983, pp. 842-856.

2. Tsuji, S. Choudary, P.V., Martin, B.M. et al. A mutation in the human glucocerebrosidase gene in neuronopathic Gaucher's disease. $N$ Engl J Med 1987, 316: 570-575.

3. Davies, G.T. \& Foreman, H.M., Haemorrhagic pericardial effusion in adult Gaucher's disease. Br Heart $J$ 1970, 32: 855-858.

4. Aderka, D., Garfinkel, D., Rothem, A. \& Pinkas, J. Fatal bleeding from esophageal varices in a patient with Gaucher's disease. Am J Gastroenterol 1982, 77: 838-839.

5. Davis, F.W., Genecin, A. \& Smith, E.W. Gaucher's disease with thrombocytopenia, an instance of selective hypersplenism. Bull Johns Hopkins Hosp 1949, 84: 176-179.

6. Lester, T.J., Grabowski, G.A., Goldblatt, J., Leiderman, I.Z. \& Zaroulis, C.G. Immune thrombocytopenia and Gaucher's disease. Am J Med 1984, 77: 569-571.

7. Green, D., Battifora, H.A., Smich, R.T. \& Rossi, E.C. Thrombocytopenia in Gaucher's disease. Ann Intern Med 1971, 74: 727-731.

8. Sack, J.H. Jr. Clinical diversity in Gaucher's disease. Johns Hopkins Med J 1980, 146: 166-170.

9. Lee, R.E. The pathology of Gaucher's disease. In: Desnick, R.J., Gatt, S. \& Grabowski, G.A. (eds). Gaucher's Disease: A Century of Delineation and Research. Alan R. Liss Inc., New York, N.Y., 1982, pp. 177-217.

10. James, S.P., Stromeyer, F.W., Chang, C. \& Barranger, J.A. Liver abnormalities in patients with Gaucher's disease. Gastroenterology 1981, 80: 126-133.

11. Fellows, K.E., Grand, R.J., Colodny, A.H., Ossini, E.N. \& Crocker, A.C. Combined portal and vena caval hypertension in Gaucher's disease: the value of preoperative venography. $J$ Pediatrics 1975, 87: 739-743.

12. Sales, J.E. \& Hunt, A.H. Gaucher's disease and portal hypertension. Br J Surg 1970, 57: 225-228.

13. Kozower, M., Kaplan, M.M., Kanfer, J.N. et al. Esophageal varices in a 60 -year old man with Gaucher's disease. Am J Dig Dis 1974, 19: 565-570. abnormalities. $^{25,26}$

The condition of our patient merited urgent surgery despite the lack of an accurate localization of bleeding preoperatively. Preoperative ileal endoscopy using the gastroscope enabled the involved area of bowel to be visualized and allowed an effective resection.

An unusual acute complication of small bowel lymphoid hyperplasia in a patient with adult Gaucher's disease is presented. Fortunately, the outcome for the patient was successful due to peroperative endoscopic localization of the affected ileum.

14. Shearman, D.J.C. \& Finlayson, N.D.C. In: Diseases of the Gastrointestinal Tract and Liver. Churchill Livingstone, Edinburgh, 1982, pp. 192-219.

15. Richter, J.M., Hedsburg, S.F., Athanaosoulis, G.A. \& Schapiro, R.H. Angiodysplasia: clinical presentation and colonoscopic diagnosis. Dig Dis Sci 1984, 29: 481-485.

16. Tedesco, F.S., Griffin, J.W. \& Kahn, A.Q. Vascular ectasia of the colon: clinical, colonoscopic and radiological features. $J$ Clin Gastroenterol 1980, 2: 233-238.

17. Max, M.H., Richardson, J.D., Flint, I.M., Knutson, C.O. \& Schwesirgen, W. Colonoscopic diagnosis of angiodysplasias of the colon. Surg Gynecol Obstet 1981, 152: 195-199.

18. Waitman, A. Laser endoscopy - The Beth Israel experience in 750 patients. Gastrointest Endosc 1985, 31: 160-174.

19. Jensen, D.H. \& Machicado, G.A. Bleeding colonic angioma: endoscopic coagulation and follow-up. (Abstract). Gastroenterology 1985, 88: 1433.

20. Alavi, A., Dann, R.W., Daum, S. \& Biery, D.N. Scintigraphic detection of acute gastrointestinal bleeding. Radiology 1977, 124: 753-756.

21. Duray, P.H., Marcal, J.M., LiVolsi, V.A., Fisher, R., Scholhamer, C. \& Brand, M.H. Small intestinal angiodysplasia in the elderly. J Clin Gastroenterol 1984, 6: 311-319.

22. Brearley, S., Hawker, P.C., Dorricot, N.J. et al. The importance of laparotomy in the diagnosis and management of intestinal bleeding of obscure origin. Ann R Coll Surg Engl 1986, 68: 245-248.

23. Bowden, T.A., Hocks, V.H. \& Mansberger, A.R. Intraoperative endoscopy, gastrointestinal endoscopy. Ann Surg 1980, 191: 680-687.

24. Forde, K.A. Intraoperative colonoscopy. In: Hunt, R.H. \& Wayne, J.D. (eds) Colonoscopy, Chapter 11. Chapman \& Hall, London, 1981, pp. 189-198.

25. Scott, S.D. \& Royle, G.T. Angiodysplasia of the small bowel, a 'brilliant' technique for localizing the quiescent lesion. Postgrad Med J 1987, 63: 995-997.

26. Lau, W.Y., Wong, S.Y., Ngan, H., Fan, S.T. \& Wong, K.K. Intra-operative localization of bleeding small intestinal lesions. Br J Surg 1988, 75: 249-251. 